\title{
Posttraumatic Atlantoaxial Rotatory Dislocation in a Healthy Adult Patient: A Case Report and Review of the Literature
}

\author{
Giuseppe Maida, Eleonora Marcati, and Silvio Sarubbo \\ Division of Neurosurgery, Department of Neuroscience and Rehabilitation, University-Hospital S. Anna, \\ 8 Via Aldo Moro, Cona, 44124 Ferrara, Italy \\ Correspondence should be addressed to Giuseppe Maida, giuma@vodafone.it
}

Received 29 August 2012; Accepted 30 September 2012

Academic Editors: M. Gotoh, M. E. Lovell, and M. K. Lyons

Copyright ( $) 2012$ Giuseppe Maida et al. This is an open access article distributed under the Creative Commons Attribution License, which permits unrestricted use, distribution, and reproduction in any medium, provided the original work is properly cited.

\begin{abstract}
Atlantoaxial rotatory dislocation (AARD) is a rare complication in adults usually leading to pain, spinal cord injury, or death. Clinical and radiological diagnosis is difficult and often delayed. We report a rare case of posttraumatic AARD in a neurological intact 27-year-old male in which initial radiographic evaluation was negative. A computed tomography (CT) scan was promptly done because the patient showed a severe torticollis. Therefore, early diagnosis, immobilisation, and surgical fusion and arthrodesis were performed. After surgery, cervical pain and torticollis were resolved and the patient remained neurologically intact with a CT scan documentation of fusion at the 3-year followup.
\end{abstract}

\section{Introduction}

Craniocervical traumas are commonly described as neurologically catastrophic events with a very low survival rate [1-4]. Moreover, occipitoatlantoaxial dislocations are often misdiagnosed on the initial radiographic and clinical evaluation [5-10]. The delay to diagnosis and treatment has been reported as a negative prognostic factor related to a poor outcome $[1,2,11]$. However, there are a few cases reporting in the literature no neurological deficit in both atlantooccipital and atlantoaxial dislocations [1, 12-15]. Besides, recent improvements in the emergency diagnostic and therapeutic management showed an increased rate of patient survival.

In this paper, we present a rare case of acute posttraumatic atlantoaxial rotatory dislocation (AARD) in a healthy adult patient who underwent early posterior occipitocervical stabilisation and arthrodesis.

\section{Case Report}

A twenty-seven-year-old male patient who had been involved in a motor vehicle accident was brought to the emergency room with multiple injuries in October 2008. The patient was not examined on arrival due to the fact that he was intubated shortly after admission for airway protection and hemodynamic instability; however, he was reported to be moving all 4 extremities at the scene. Neutral cervical spine radiographs performed under general anaesthesia revealed no fracture or dislocation. The patient was estubated after a few days and he was found to have a severe torticollis with his head rotated to the left side and tilted toward the right side in a "cock-robin" position, muscles spasms, painful limitation of motion, and inability to turn the head to the right side. However, the neurological examination was normal. At this time, a computed tomography (CT) of the cervical spine with a bone window was performed showing an atlantodental interval (ADI) greater than $5 \mathrm{~mm}$ (Figure 1(a)), 45 degrees of axial rotation (Figure 1(b)), and no bone fracture. Additionally, an asymmetry of the lateral masses of $\mathrm{C} 1$ with respect to the odontoid process was seen on the anteroposterior CT bone scan image and a loss of normal articular apposition at C1-C2 was documented (Figure 1(c)). Furthermore, a magnetic angioresonance was performed to rule out the risk of injury to the vertebral arteries. 


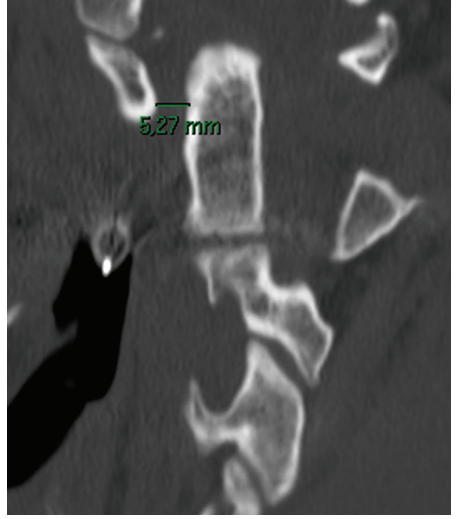

(a)

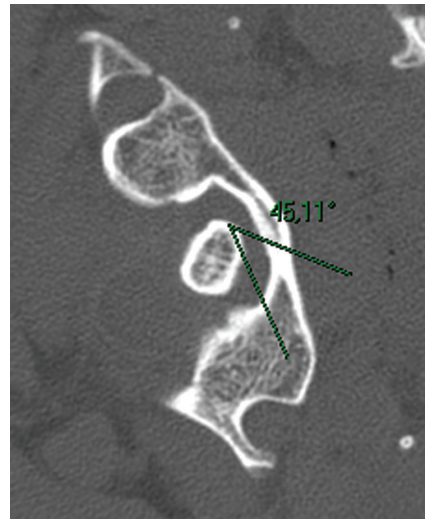

(b)

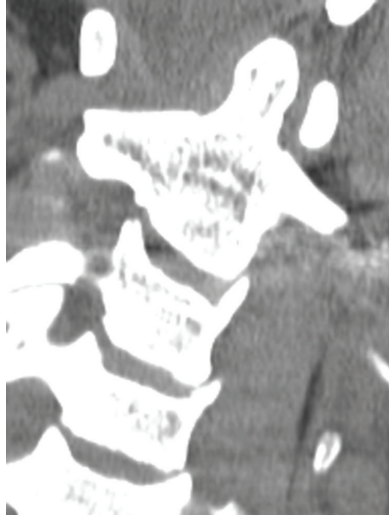

(c)

Figure 1: Computed tomography scans showing an atlanto-dental interval greater than $5 \mathrm{~mm}$ (a), 45 degrees of rotation (b), and asymmetry of the lateral masses of $\mathrm{C} 1$ (c).

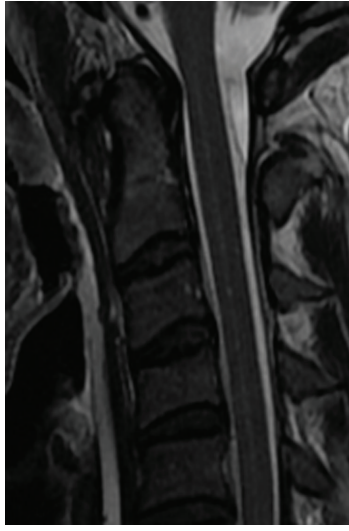

(a)

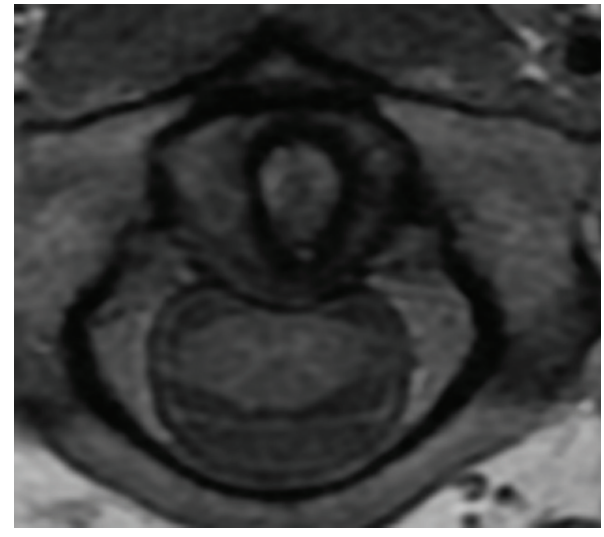

(b)

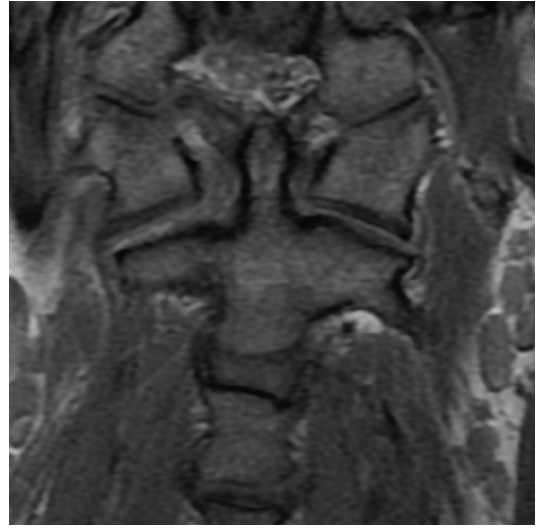

(c)

FIGURE 2: Cervical magnetic resonance imaging showing injury of ligament: midsagittal (a), axial (b), and coronal (c) view.

A manual manipulation was then attempted under general anaesthesia and a quite complete reduction was confirmed with CT bone scan. At this time, a new cervical spine magnetic resonance imaging was performed to determine the disruption of ligaments revealing soft tissues swelling, a Type IA injury of transverse ligament, a complete rupture of the right alar ligament, and a partial injury of the left one (Figures 2(a), 2(b), and 2(c)). No spinal cord compression or signal changes were identified.

Finally, the patient was placed in a Philadelphia collar and he was transported directly to the operating room. An early posterior stabilisation from the occiput to C3 was performed by using a Hartshill U-shaped rod and Songer sublaminar wires. Moreover, an autologous bone graft, a porcine xenograft, and a biocompatible graft substitute like hydroxyapatite were placed in the decorticated areas. In addition, initial and intraoperative motor and somatosensory evoked potentials suggested no neurological modifications. The postoperative neurological examination did not reveal any deficit and the torticollis was completely resolved. After surgery, the patient was placed in a Philadelphia collar for 60 days. Immediate postoperative radiographs showed a proper implant placement (Figure 3). CT bone scans at 60-day and 3-year followup demonstrated an occipitocervical stable fusion (Figure 4); furthermore, the patient was free of pain and torticollis and returned to his normal daily activities.

\section{Discussion}

Craniovertebral junction (CVJ) is a complicated anatomical and functional structure representing the transition between the skull and the spine which allows the extension, flexion, and lateral rotation of the head [16]. In particular, the atlanto-axial segment has singular characteristics when compared with the inferior cervical vertebrae specifically because of its higher range of rotation [5].

AARD is a rare pathology of the upper cervical spine in which the physiological replacement to the neutral position after a rotational movement of the head is not allowed [5]. It was described in 1907 by Corner, for the first time [17], and over the past three decades a total of 16 cases were reported in the literature $[5,6,9,10,18-$ 30]. Although the pathogenesis is still not well defined, two major hypotheses are suggested in this regard: the 


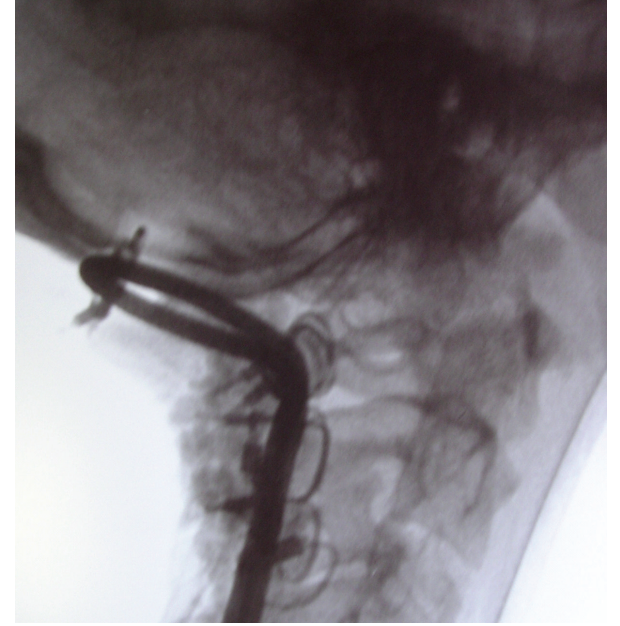

FIGURE 3: Immediate postoperative radiographs showing the occipitocervical fusion.

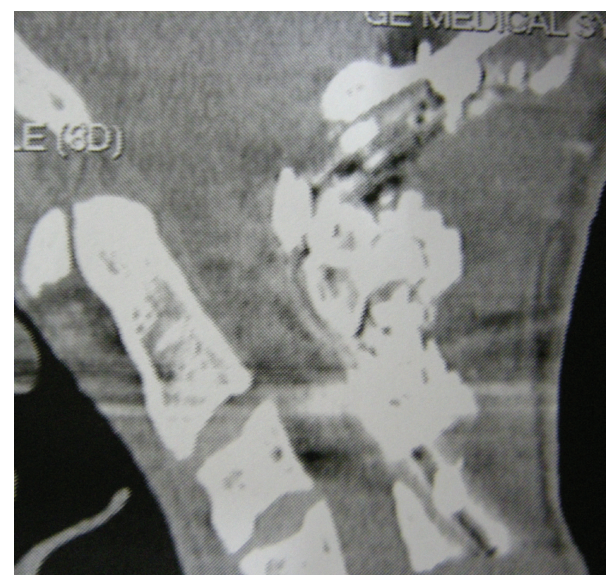

Figure 4: Computed tomography scan showing an occipitocervical stable fusion at the 3-year followup.

interposition of synovia as a mechanical obstacle and the partial or total injury of the main ligamentous structures that normally limit the excessive anterior shift and rotation (the transverse and the alar ligaments, resp.) $[6,10,31,32]$. Generally, traumatic events or infections may cause the AARD. Nevertheless other conditions can be also associated, such as inflammation of the nasopharynx, postoperative procedures involving the head and the neck, congenital laxity of ligaments (i.e., Down's syndrome, Marfan's syndrome, or rheumatoid arthritis), metastatic tumors, and eosinophilic granulomas [1, 10, 33-39]. Posttraumatic AARD is very rare in adults probably because it is often related to lethal injuries due to a severe associated trauma $[10,18,19,24,35,40-42]$. However, many authors suggest that the higher incidence of AARD in children may be dependent to specific anatomical features, such as a more horizontal and shallow joint surface of the lateral mass, a relative elasticity of the ligaments, notfully developed neck muscles, and a relatively large head $[7,10,22,28,43,44]$. Fielding and Hawkins described 4 types of AARD (Table 1) [6]. This classification, which has been
TABLE 1: Classification of AARD by Fielding and Hawkins [6].

\begin{tabular}{lcc}
\hline Type & Injury of transverse ligament & ADI \\
\hline $\begin{array}{l}\text { Type I } \\
\text { Type II }\end{array}$ & None & Mild \\
Type III & $\begin{array}{c}\text { Deficiency both of the transverse } \\
\text { and alar ligaments }\end{array}$ & $3-5 \mathrm{~mm}$ \\
Type IV & $\begin{array}{c}\text { Deficiency both of the transverse } \\
\text { and alar ligaments }\end{array}$ & $\begin{array}{c}\text { Posterior shift of } \\
\text { the atlas }\end{array}$ \\
\hline * Adapted by Kim et al.,2007 [34].
\end{tabular}

TABLE 2: Classification of transverse ligament injuries byDickman et al. [45].

\begin{tabular}{ll}
\hline Type & Injury of transverse ligament \\
Type I & Disruption of ligament substance \\
& (A) Midportion \\
& (B) Periosteal insertion \\
& Disconnection of the tubercle of insertion from the \\
Type II & (A) lateral mass \\
& (B) Avulsion with an intact C1 lateral mass \\
\hline
\end{tabular}

widely accepted, correlates with an increasing risk of spinal instability and potential neurological impairment [35]. This case was categorized as Type III for both the increase of ADI and the injury of ligaments.

Moreover, Dickman et al. have classified the injuries involving the transverse atlantal ligament or its osseous insertions (Table 2). In this classification, the disruption of the ligamentous substance was named as Type I and fractures or avulsions involving the tubercle which affords insertion of the transverse ligament on the $\mathrm{C} 1$ lateral mass were named as Type II. Type I injuries, as in our case, are considered incapable of healing without internal fixation and they should be treated with early surgery [45].

Accordingly, in our case, we decided to perform an early internal fixation extended from occiput to C3. In fact, they were documented either the injury of the transverse ligament and the injury of alar ligaments thus compromising the stability of $\mathrm{C} 1-\mathrm{C} 2$ and $\mathrm{C} 0-\mathrm{C} 1$, respectively $[1-3,5,45]$. In addition, the 45 degrees of atlanto-axial rotator dislocation and the increase of the ADI to $4 \mathrm{~mm}$ met the $\mathrm{C} 0-\mathrm{C} 2$ instability criteria as described by White and Panjabi [44]. In these cases, an occipito-cervical fusion procedure is generally considered as neuroprotective and should be performed as early as possible [1, 46-49].

Numerous surgical techniques were proposed for the occipito-cervical fusion [50-57]. Until now, there is no Class I evidence about the use of wires or screw. The wiring/rod method is probably one of the simplest, least expensive, and most widely available worldwide. This method allows the reduction of the dislocation and provides immediate rigid fixation [57].

Although immediate fixation is achieved, long-term stability can be improved by bone arthrodesis and we have thus included grafting [58-60]. 


\section{Conclusion}

The diagnosis of AARD should be suspected each time torticollis and cervical pain are associated. However, the AARD can also occur in the absence of any clinical sign and thus it should be systematically considered and excluded in any traumatic patient. The radiographic findings on the usual anteroposterior and lateral radiographs of the cervical spine may be difficult to interpret because of the rotatory deformity. Therefore, the CT scan is to be considered the gold standard and it must be promptly provided. Moreover, magnetic resonance imaging is also mandatory to rule out neurovascular injuries and to identify eventual ligamentous ruptures. When instability of the craniovertebral junction is diagnosed, early reduction and fusion are the recommended definitive treatments to prevent neurologic deterioration and vertebral arteries injury. Although numerous surgical techniques have been developed, to achieve a successful outcome surgeons should be familiar with the atlanto-axial complex and the selected method. We chose the wiring/rod method which is simpler, less expensive and provides immediate semirigid fixation and excellent fusion results.

\section{Conflict of Interests}

The authors report neither conflict of interests concerning this study nor personal financial or institutional interest in any of the materials or devices described in this paper.

\section{References}

[1] E. Bisson, A. Schiffern, M. D. Daubs, D. S. Brodke, and A. A. Patel, "Combined occipital-cervical and atlantoaxial disassociation without neurologic injury: case report and review of the literature," Spine, vol. 35, no. 8, pp. E316-E321, 2010.

[2] C. Bellabarba, S. K. Mirza, G. A. West et al., "Diagnosis and treatment of craniocervical dislocation in a series of 17 consecutive survivors during an 8-year period," Journal of Neurosurgery: Spine, vol. 4, no. 6, pp. 429-440, 2006.

[3] V. C. Traynelis, G. D. Marano, R. O. Dunker, and H. H. Kaufman, "Traumatic atlanto-occipital dislocation. Case report," Journal of Neurosurgery, vol. 65, no. 6, pp. 863-870, 1986.

[4] A. H. Van den Bout and G. F. Dommisse, "Traumatic atlantooccipital dislocation," Spine, vol. 11, no. 2, pp. 174-176, 1986.

[5] G. Y. El-Khoury, C. R. Clark, and A. W. Gravett, "Acute traumatic rotatory atlanto-axial dislocation in children. A report of three cases," Journal of Bone and Joint Surgery. Series A, vol. 66, no. 5, pp. 774-777, 1984.

[6] J. W. Fielding and R. J. Hawkins, "Atlanto axial rotary fixation. (Fixed rotatory subluxation of the atlanto axial joint)," Journal of Bone and Joint Surgery. Series A, vol. 59, no. 1, pp. 37-44, 1977.

[7] N. J. Goddard, J. Stabler, and J. S. Albert, "Atlanto-axial rotatory fixation and fracture of the clavicle. An association and a classification," Journal of Bone and Joint Surgery. Series $B$, vol. 72, no. 1, pp. 72-75, 1990.

[8] W. Oberthaler and E. Schwarz, "Delayed diagnosis of a spontaneous atlanto-axial rotatory dislocation," Archives of
Orthopaedic and Traumatic Surgery, vol. 103, no. 3, pp. 212214, 1984.

[9] W. A. Phillips and R. N. Hensinger, "The management of rotatory atlanto-axial subluxation in children," Journal of Bone and Joint Surgery. Series A, vol. 71, no. 5, pp. 664-668, 1989.

[10] M. Weißkopf, D. Naeve, M. Ruf, J. Harms, and D. Jeszenszky, "Therapeutic options and results following fixed atlantoaxial rotatory dislocations," European Spine Journal, vol. 14, no. 1, pp. 61-68, 2005.

[11] M. G. Fehlings and R. G. Perrin, "The timing of surgical intervention in the treatment of spinal cord injury: a systematic review of recent clinical evidence," Spine, vol. 31, no. 11, supplement, pp. S28-S35, 2006.

[12] V. J. De De Beer, M. Thomas, J. Walters, and P. Anderson, "Traumatic atlanto-axial subluxation," Journal of Bone and Joint Surgery. Series B, vol. 70, no. 4, pp. 652-655, 1988.

[13] T. Dibenedetto and C. K. Lee, "Traumatic atlanto-occipital instability: a case report with follow-up and a new diagnostic technique," Spine, vol. 15, no. 6, pp. 595-597, 1990.

[14] C. Ide, J. F. Nisolle, N. Misson et al., "Unusual occipitoatlantal fracture dissociation with no neurological impairment. Case report," Journal of Neurosurgery, vol. 88, no. 4, pp. 773-776, 1998.

[15] J. P. Salinsky, G. J. Scuderi, and A. H. Crawford, "Occipitoatlanto-axial dissociation in a child with preservation of life: a case report and review of the literature," Pediatric Neurosurgery, vol. 43, no. 2, pp. 137-141, 2007.

[16] A. H. Menezes, "Craniocervical fusions in children," Journal of Neurosurgery, vol. 9, pp. 573-585, 2012.

[17] E. M. Corner, "Rotatory dislocation ofthe atlas," Annals of Surgery, vol. 14, pp. 9-26, 1907.

[18] N. Boos, R. Khazim, R. W. Kerslake, J. K. Webb, and H. Mehdian, "Atlanto-axial dislocation without fracture: case report of an ejection injury," Journal of Bone and Joint Surgery. Series B, vol. 79, no. 2, pp. 204-205, 1997.

[19] L. Bouchez and C. Camelot, "Instabilités et luxations atloidoaxoidiennes," in Traitement des Lesions Traumatiques Récentes du Rachis. Troisième Journée de Traumatologie de la Pitié Salpétrière, G. Saillant, C. Camelot, and S. Ramare, Eds., pp. 59-77, Sauramps Médical, Montpellier, France, 1997.

[20] A. Hicazi, E. Acaroglu, A. Alanay, M. Yazici, and A. Surat, "Atlantoaxial rotatory fixation-subluxation revisited: a computed tomographic analysis of acute torticollis in pediatric patients," Spine, vol. 27, no. 24, pp. 2771-2775, 2002.

[21] R. N. Jones, "Rotatory dislocation of both atlanto-axial joints," Journal of Bone and Joint Surgery. Series B, vol. 66, no. 1, pp. 67, 1984.

[22] P. Kehr, M. Mitteau, J. P. Steib et al., "Rotationsluxation C1/C2 nach chiropraktischer manipulation bei einer junger patientin," Diagnose Und Behandlung. Manuelle Medizin, vol. 27, pp. 11-13, 1989.

[23] K. R. Moore and E. H. Frank, "Traumatic atlantoaxial rotatory subluxation and dislocation," Spine, vol. 20, no. 17, pp. 19281930, 1995.

[24] P. A. Robertson and H. A. P. Swan, "Traumatic bilateral rotatory facet dislocation of the atlas on the axis," Spine, vol. 17, no. 10, pp. 1252-1254, 1992.

[25] R. Roy-Camille, "Luxations rotatoires C1-C2," in Rachis Cervical Supérieur, Cinquièmes Journées d'Orthopédie de " La Pitié", pp. 94-98, Masson, Paris, France, 1986.

[26] R. Sinigaglia, A. Bundy, U. Nena et al., "Traumatic atlantoaxial rotatory dislocation in adults," GIOT, vol. 34, no. 2, pp. 183191, 2008. 
[27] B. R. Subach, M. R. McLaughlin, A. L. Albright, and I. F. Pollack, "Current management of pediatric atlantoaxial rotatory subluxation," Spine, vol. 23, no. 20, pp. 2174-2179, 1998.

[28] M. Vinchon, R. Assaker, X. Leclerc, J. P. Lejeune, E. C. Benzel, and V. K. H. Sonntag, "Vertebrobasilar insufficiency resulting from traumatic atlantoaxial instability: case report," Neurosurgery, vol. 36, no. 4, pp. 839-841, 1995.

[29] J. J. Wise, R. Cheney, and J. Fischgrund, "Traumatic bilateral rotatory dislocation of the atlanto-axial joints: a case report and review of the literature," Journal of Spinal Disorders, vol. 10, no. 5, pp. 451-453, 1997.

[30] M. B. Coutts, "Atlanto-epistropheal subluxations," Archives of Surgery, vol. 29, pp. 297-231, 1934.

[31] G. Wortzman and F. P. Dewar, "Rotary fixation of the atlantoaxial joint: rotational atlantoaxial subluxation," Radiology, vol. 90, no. 3, pp. 479-487, 1968.

[32] P. Grisel, "Énucléation de l'atlas et torticollis nasopharyngien," La Presse Médicale, vol. 38, pp. 50-57, 1930.

[33] A. Herzka, P. D. Sponseller, and R. E. Pyeritz, "Atlantoaxial rotatory subluxation in patients with Marfan syndrome: a report of three cases," Spine, vol. 25, no. 4, pp. 524-526, 2000.

[34] Y. S. Kim, J. K. Lee, S. J. Moon, and S. H. Kim, "Post-traumatic atlantoaxial rotatory fixation in an adult: a case report," Spine, vol. 32, no. 23, pp. E682-E687, 2007.

[35] B. C. Marar and N. Balachandran, "Non traumatic atlanto axial dislocation in children," Clinical Orthopaedics and Related Research, vol. 92, pp. 220-226, 1973.

[36] G. M. White and W. L. Healy, "Tumor-associated Atlanto-axial rotatory fixation: a case report," Spine, vol. 12, no. 4, pp. 406408, 1987.

[37] B. C. Wilson, B. L. Jarvis, and R. C. Haydon, "Nontraumatic subluxation of the atlantoaxial joint: Grisel's syndrome," Annals of Otology, Rhinology and Laryngology, vol. 96, no. 6, pp. 705-708, 1987.

[38] J. W. Wolf Jr. and S. G. Kahler, "Atlanto-axial rotatory fixation associated with the 18q- syndrome. Case report," Journal of Bone and Joint Surgery. Series A, vol. 62, no. 2, pp. 295-297, 1980.

[39] C. T. Born, A. J. Mure, W. M. Iannacone, and W. G. DeLong, "Three-dimensional computerized tomographic demonstration of bilateral atlantoaxial rotatory dislocation in an adult: report of a case and review of the literature," Journal of orthopaedic trauma, vol. 8, no. 1, pp. 67-72, 1994.

[40] E. Castel, J. Benazet, C. Samaha, N. Charlot, O. Morin, and G. Saillant, "Delayed closed reduction of rotatory atlantoaxial dislocation in an adult," European Spine Journal, vol. 10, no. 5, pp. 449-453, 2001.

[41] Y. Lefebvre, S. R. Babin, P. Clavert et al., "Traumatic bilateral rotatory atlantoaxial dislocation in an adult: case report and review of the literature," Revue de Chirurgie Orthopedique et Reparatrice de l'Appareil Moteur, vol. 88, no. 6, pp. 613-619, 2002.

[42] A. Radek, K. Zapałowicz, M. Grochal et al., "Post-traumatic unilateral atlanto-axial rotatory subluxation in an adult," Neurologia I Neurochirurgia Polska, vol. 37, no. 4, pp. 935-942, 2003.

[43] N. Kawabe, H. Hirotani, and O. Tanaka, "Pathomechanism of atlantoaxial rotatory fixation in children," Journal of Pediatric Orthopaedics, vol. 9, no. 5, pp. 569-574, 1989.

[44] A. A. White and M. M. Panjabi, "The clinical biomechanics of the occipitoatlantoaxial complex," Orthopedic Clinics of North America, vol. 9, no. 4, pp. 867-878, 1978.
[45] C. A. Dickman, K. A. Greene, and V. K. H. Sonntag, "Injuries involving the transverse atlantal ligament: classification and treatment guidelines based upon experience with 39 injuries," Neurosurgery, vol. 38, no. 1, pp. 44-50, 1996.

[46] J. Dvorak, E. Schneider, P. Saldinger, and B. Rahn, "Biomechanics of the craniocervical region: the alar and transverse ligaments," Journal of Orthopaedic Research, vol. 6, no. 3, pp. 452-461, 1988.

[47] S. Hamai, K. Harimaya, T. Maeda, A. Hosokawa, J. I. Shida, and Y. Iwamoto, "Traumatic atlanto-occipital dislocation with atlantoaxial subluxation," Spine, vol. 31, no. 13, pp. E421E424, 2006.

[48] M. B. Harris, M. J. Duval, J. A. Davis, and P. M. Bernini, "Anatomical and roentgenographic features of atlantooccipital instability," Journal of Spinal Disorders, vol. 6, no. 1, pp. 5-10, 1993.

[49] R. S. Jackson, D. M. Banit, A. L. Rhyne III, and B. V. Darden II, "Upper cervical spine injuries," The Journal of the American Academy of Orthopaedic Surgeons, vol. 10, no. 4, pp. 271-280, 2002.

[50] U. M. Ahn, M. A. Lemma, N. U. Ahn, A. J. Khanna, J. Buchowski, and J. P. Kostuik, "Occipitocervical fusion: a review of indications, techniques of internal fixation, and results," Neurosurgery Quarterly, vol. 11, no. 2, pp. 77-85, 2001.

[51] H. S. An, "Internal fixation of the cervical spine: current indications and techniques," Journal of the American Academy of Orthopaedic Surgeons, vol. 3, pp. 194-206, 1995.

[52] G. H. Stock, A. R. Vaccaro, A. K. Brown, and P. A. Anderson, "Contemporary posterior occipital fixation," Instructional course lectures, vol. 56, pp. 319-328, 2007.

[53] F. L. Vale, M. Oliver, and D. W. Cahill, "Rigid occipitocervical fusion," Journal of Neurosurgery, vol. 91, no. 2, supplement, pp. 144-150, 1999.

[54] J. R. Vender, A. J. Rekito, S. J. Harrison, and D. E. McDonnell, "The evolution of posterior cervical and occipitocervical fusion and instrumentation," Neurosurgical Focus, vol. 16, no. 1, p. E9, 2004.

[55] M. Visocchi, F. Di Rocco, M. Meglio, and A. Maciejczak Tamow, "Craniocervical junction instability: instrumentation and fusion with titanium rods and sublaminar wires. Effectiveness and failures in personal experience," Acta Neurochirurgica, vol. 145, no. 4, pp. 265-272, 2003.

[56] S. B. Wertheim and H. H. Bohlman, "Occipitocervical fusion. Indications, technique, and long-term results in thirteen patients," Journal of Bone and Joint Surgery. Series A, vol. 69, no. 6, pp. 833-836, 1987.

[57] C. D. Winegar, J. P. Lawrence, B. C. Friel et al., "A systematic review of occipital cervical fusion: techniques and outcomes: a review," Journal of Neurosurgery: Spine, vol. 13, no. 1, pp. 5-16, 2010.

[58] A. J. Belzberg and B. I. Tranmer, "Stabilization of traumatic atlanto-occipital dislocation. Case report," Journal of Neurosurgery, vol. 75, no. 3, pp. 478-482, 1991.

[59] N. E. Epstein, "An argument for traditional posterior cervical fusion techniques: evidence from 35 cases," Surgical Neurology, vol. 70, no. 1, pp. 45-51, 2008.

[60] A. I. MacKenzie, D. Uttley, H. T. Marsh, and B. A. Bell, "Craniocervical stabilization using Luque/Hartshill rectangles,” Neurosurgery, vol. 26, no. 1, pp. 32-36, 1990. 


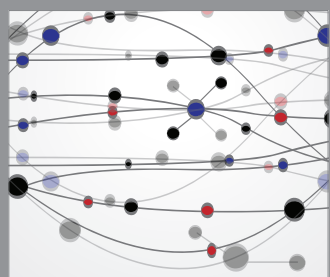

The Scientific World Journal
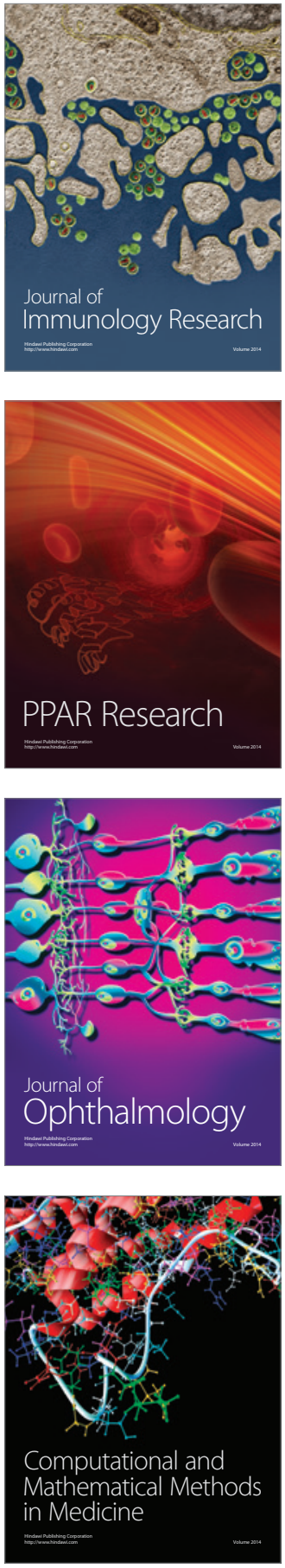

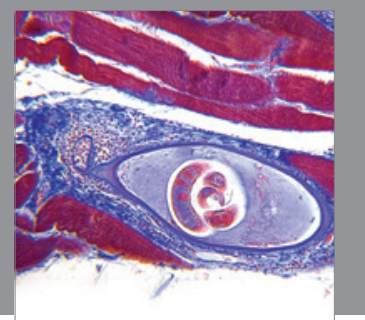

Gastroenterology

Research and Practice
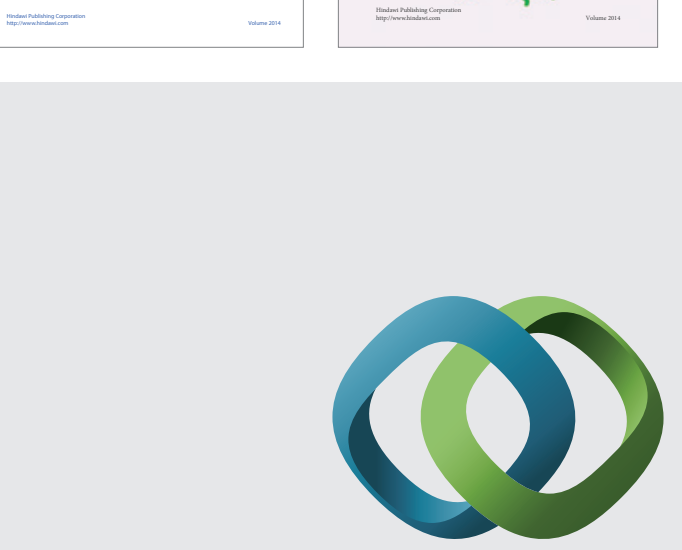

\section{Hindawi}

Submit your manuscripts at

http://www.hindawi.com
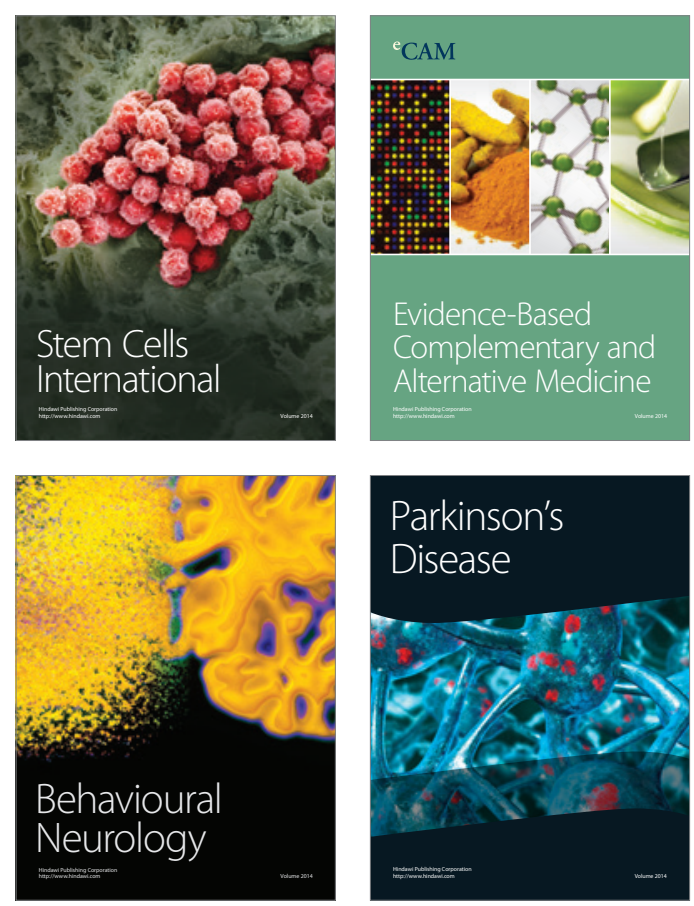

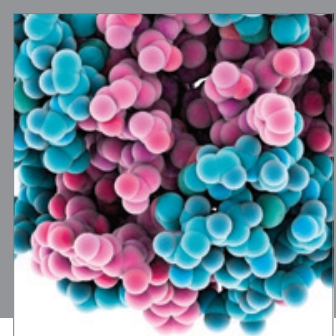

Journal of
Diabetes Research

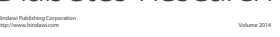

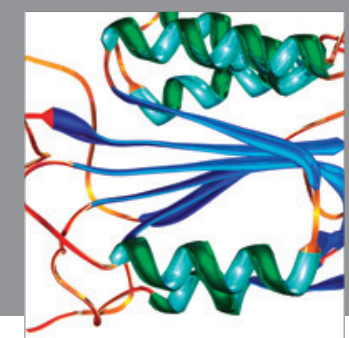

Disease Markers
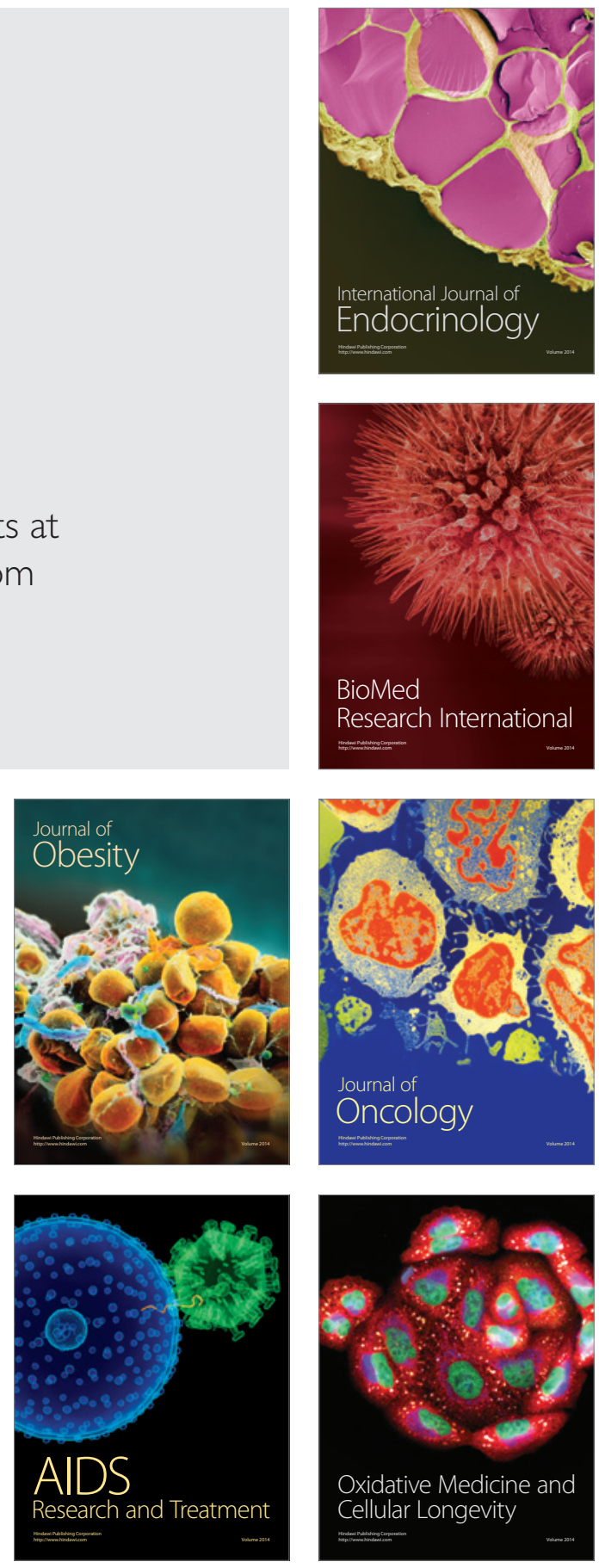